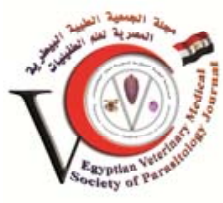

Original Article

\title{
Studies on Blood and Enteric Protozoans Infecting Camels At Behera Province, Egypt
}

Eman A Khedr ${ }^{1}$, Sherif K El-

Shanat ${ }^{2}$, Reda S Fadly ${ }^{1}$,

Mohamed Y Alsokkary², Yehia Z Otify $^{2}$

${ }^{1}$ Animal Health Research

Institute, Damnhour branch

${ }^{2}$ Department of Parasitology, Faculty of Veterinary Medicine, Alexandria University

\begin{abstract}
:
This study was carried out to investigate the prevalence of blood and enteric protozoan parasites in freshly slaughtered camels at Behera Province, during the years of 2014 and 2015. 120 (66 male and 54 female) freshly slaughtered camels were examined, 94 (46 males and 48 females) $(78.3 \%$ ) were found to be infected with enteric protozoa, while 63 camels $(24$ males and 39 females) $(52.5 \%)$ were found to be infected with blood protozoa. Concerning enteric protozoa, the highest rate was recorded for Diplodinium spp. (58\%), followed by Cryptosporidium parvum. (24.16\%), then Eimeria spp (13.33\%). Eimaria spp. were E.camili (50\%), E. dromedarii (31.25\%) and, E. pellerdyi (18.75\%). Giardia intestinalis, (5\%) and Balantidium coli $(4.16 \%)$. The prevalence of blood protozoa revealed that the highest rate was for Theileria spp., then Anaplasma marginale and Trypanosoma evansi 45.82, 15.8 and 1.66\%, respectively. Regarding, seasonal dynamics of enteric protozoan parasites, Cryptosporidium parvum, Eimeria spp and Diplodinium spp showed their highest incidence during Winter, while Balantidium coli recorded the highest rate during Spring. Summer had the highest rate for Theileria spp. but there were abundance of Anaplasma marginale during spring and Autumn. Finally, Trypanosoma evansi were only found during winter and autumn.
\end{abstract}

Key words: Camel; blood protozoa; enteric protozoa; prevalence; Egypt

\section{INTRODUCTION}

Camels are multipurpose animals in many places of the world because they are reared up for their meat, milk, hair and hides production, which could be as a source of additional income to nomadic herder. In Egypt, camels are mostly raised for meat consumption and other purposes, the imported camels mostly pass through Daraw quarantine at Aswan province. These camels come from different localities in Africa specially Sudan which has one of the largest populations of the one humped camels all over the world. Such importation may lead to the development and introduction of exotic diseases (AbdAllah, 2007). Camels are susceptible to wide range of parasites that may cause many problems especially blood and gastrointestinal ones. The importance of blood parasites is not only as a direct cause of death but also affect the general health condition of camels Theileria spp is a tick-borne protozoan parasite belonging to the Phylum Apicomplexa (Boulter and Hall, 1999). Two species, namely Theileria camelensis and dormedarii have been reported from camel breeding areas of the world (Chhabra and Sangwan, 2006). Protozoal diseases particularly trypanosomosis, cause remarkable losses on animal production in all tropical and subtropical areas.
Trypanosomosis in camels is caused by Trypanosoma evansi and is transmitted from camel to camel by a number of species of haematophagous biting flies including Tabanus, Stomoxys, Lyperosia and Haematobia spp. (Stewart et al., 1996). T. evansi infection is a prevalent disease in camels (Camelus dromedarius), that causes considerable economic losses due to weakness, abortion in pregnant animals, and weight loss. In addition, the fatality rate resulted from trypanosomiasis may reach $100 \%$ in untreated camels (Derakhshanfar et al., 2010).

In Egypt, T. evansi in camels is enzootic and consider the fore-most impediment to dromedary camel productivity (Amer et al., 2011). Anaplasmosis, the tick-borne disease, is caused by an obligateintra erythrocytic ricketsial microorganism, Anaplasma marginale (A. marginale), of the order Rickettsiales, family anaplasmataceae. Coccidian parasites comprise of a large group of obligatory intracellular parasites (Duszynski et al., 1999). The coccidian genera, Eimeria and Isospora both infect camels, however only Eimeria species were recognized as the causing disease (Kaufmann 1996). Five reported Eimeria spp. have the capability to infect camels. They are intestinal parasites (Kaufmann, 1996 and Yakhchali and 
Cheraghi, 2007). Cryptosporidiosis is one of the important zoonotic diseases caused by Cryptosporidium spp.; Cryptosporidium (C.) muris, C. parvum and C. andersoni are three species found in camelids (Wang et al., 2008). Balantidium coli (B. coli) is a ciliate protozoan and is frequently found in the intestinal tract of over 50 species of vertebrates, such as swine, human, non-human primates, and ruminants. In most cases, $B$. coli lives as a commensal organism in healthy human and animals. However, it is believed that under certain circumstances, B. coli may act as an opportunistic pathogen via the invasion of intestinal epithelium damaged by other infectious agents. Intestinal flagellates Giardia intestinalis, (G. duodenalis, or G. lamblia) infection occurs in a wide range of domestic and wild animals and also humans. $G$. intestinalis is a potential pathogen in livestock, causing diarrhea, weight loss, poor condition and lethargy (Hunter and Thompson, 2005). Also, Diplodinium spp. was the dominant in camel ciliated. Selim et al. (1996) stated the first description of Diplodinium spp. in Egypt detected in camel forestomach contents. ORDER: Entodinomorphida, FAMILY: Ophr yoscolecidae, SUBFAMILY: Diplodininae, GENUS: Diplodinium

\section{MATERIALS AND METHODS}

\section{Materials:}

The present study was conducted in Behera province. A total number of 120 camels of different ages ( 3 to 9 years) and sex were examined during 2014 and 2015. Blood specimens were collected from the ear veins for investigation of the blood protozoa. As well as, the detection of enteric protozoa has been done by collection of fresh fecal specimens and forestomach contents. These specimens were subjected to laboratory investigations for studying the prevalence of blood and enteric protozoal infection among camels.

\section{Methods:}

Collection of blood and preparation of stained blood smears: Specimens of $5 \mathrm{ml}$ of blood from ear vein were collected in screw capped tubes containing $0.5 \mathrm{ml}$ of $1 \%$ Ethylene Diamine Tetra-Acetic acid (EDTA) solution and gently mixed. Thin blood smears were made, according to (Adam et al., 1971), stained by Giemsa's stain.

Examination of enteric protozoa: Concentration flotation technique using saturated salt solution was used according to (Soulsby, 1982), for detection of Eimeria spp. oocysts. The positive fecal samples were sporulated using $2.5 \%$ potassium dichromate solution for two weeks. Thin fecal smears were stained using Modified Zhiel-Neelsen staining technique (MZN) for the detection of Cryptosporidium oocyst according to (Henriksen and Pohlenz, 1981). Both blood and enteric specimens were microscopically examined according to the methods described by (Higgins, 1986).

\section{RESULTS}

The incidence of the identified parasites Theileria spp. Trypanosoma evansi, Anaplasm marginale a, Cryptosporidium parvum, Eimeria spp., Balantidium coli, Giardia intestinalis and Diplodinium spp. were 45.82, 1.66, 15.8, 24.16,13.33, 4.16, 5 and 58\% respectively (Table 1).

Blood parasites: Out of 120 freshly slaughtered and examined camels 55 (45.82\%) were positive for Theileria spp. Out of 55 detected cases, 30 males and 25 females were found to be positive, (Table 3). Seasonal profile of Table 1: General incidence of blood and enteric protozoa in dromedary camels

\begin{tabular}{lccc}
\hline & $\begin{array}{c}\text { The examined } \\
\text { specimens }\end{array}$ & $\begin{array}{c}\text { Positive } \\
\text { (+ve) }\end{array}$ & $\%$ \\
\hline Blood parasites & 120 & 2 & 1.66 \\
$\quad$ Trypanosoma. evansi & 120 & 55 & 45.82 \\
$\quad$ Theileria spp. & 120 & 19 & 15.8 \\
$\quad \begin{array}{l}\text { Anaplasma marginale } \\
\text { Enteric protozoa }\end{array}$ & & & \\
$\quad$ Cryptosporidium parvum & 120 & 29 & 24.16 \\
$\quad$ Eimeria spp. & 120 & 16 & 13.33 \\
$\quad$ Balantidium coli & 120 & 5 & 4.16 \\
$\quad$ Giardia intestinalis & 120 & 6 & 5 \\
$\quad$ Diplodinium spp. & 120 & 70 & 58 \\
\hline
\end{tabular}

Table 2: Seasonal prevalence of blood parasites infecting dromedary camels

\begin{tabular}{|c|c|c|c|c|c|c|c|}
\hline \multirow{2}{*}{ Season } & \multirow{2}{*}{ No. of the } & \multicolumn{2}{|c|}{ Theileria spp. } & \multicolumn{2}{|c|}{ Anaplasma marginale } & \multicolumn{2}{|c|}{ Trypanosoma evansi } \\
\hline & & +ve & $\%$ & +ve & $\%$ & +ve & $\%$ \\
\hline Winter & 30 & 12 & 40 & 4 & 13.33 & 1 & 3.33 \\
\hline Spring & 30 & 14 & 46.66 & 6 & 20 & 0 & 0 \\
\hline Summer & 30 & 15 & 50 & 3 & 10 & 0 & 0 \\
\hline Autumn & 30 & 14 & 46.66 & 6 & 20 & 1 & 3.33 \\
\hline Total & 120 & 55 & 45.83 & 19 & 15.83 & 2 & 1.66 \\
\hline
\end{tabular}


Table 3: General incidence of enteric protozoa in relation to sex

\begin{tabular}{|c|c|c|c|c|c|c|}
\hline \multirow[b]{2}{*}{ Parasites } & \multicolumn{3}{|c|}{ No of positive } & \multicolumn{3}{|c|}{ No of negative } \\
\hline & $\begin{array}{l}\text { Males } \\
\text { +ve (\%) }\end{array}$ & $\begin{array}{l}\text { Female } \\
\text { +ve (\%) }\end{array}$ & $\begin{array}{c}\text { Total }(n=120) \\
\text { +ve }(\%)\end{array}$ & Males & Females & Total \\
\hline Cryptosporidium parvum & $15(51.7)$ & $14(48.3)$ & $29(24.2)$ & 51 & 40 & 91 \\
\hline Eimeria spp. & $9(56.3)$ & $7(43.8)$ & $16(13.3)$ & 57 & 47 & 104 \\
\hline Balantidium coli & $2(40.0)$ & $3(60.0)$ & $5(4.2)$ & 64 & 51 & 115 \\
\hline Giardia intestinalis & $2(33.3)$ & $4(66.7)$ & $6(5.0)$ & 64 & 50 & 114 \\
\hline Diplodinium spp. & $35(50.0)$ & $35(50.0)$ & $70(58.0)$ & 31 & 19 & 50 \\
\hline Trypanosoma. evansi & $1(50.0)$ & $1(50.0)$ & $2(1.7)$ & 65 & 53 & 118 \\
\hline Theileria spp. & $30(54.5)$ & $25(45.5)$ & $55(45.8)$ & 36 & 29 & 65 \\
\hline Anaplasma marginale & $10(52.6)$ & $9(47.4)$ & $19(15.8)$ & 56 & 45 & 101 \\
\hline
\end{tabular}

the identified Theileria spp indicated that, the highest incidence in summer reached to $50 \%$, followed by both spring and autumn $46.66 \%$, then winter $40 \%$, (Table 2). Out of 120 freshly slaughtered and examined camels 2 (1.66\%), were positive for Trypanosoma evansi Out of 2 detected cases, 1 male (50\%) and 1 female (50\%) were found to be positive. While, the seasonal dynamics of Trypanosoma evansi was in winter and autumn only $3.33 \%$ (Table 2). Out of 120 freshly slaughtered and examined camels 19 (15.8\%) were positive for Anaplasma marginale. Out of 19 detected cases, 10 males (52.63\%) and 9 females (47.36\%) were found to be positive, (Table 3) Seasonal incidence of Anaplasma marginale showed that, the highest prevalence was found in both spring and autumn $20 \%$, followed by winter $13.33 \%$ then summer $10 \%$, (Table 2, Fig. 1, 2, 3).

\section{Enteric protozoa}

Cryptosporidium parvum : Out of 120 examined camel's fecal specimens 29 (24.16\%) were found to be positive for Cryptosporidium parvum (Table 1). Out of 29 detected cases, 15 males (51.72\%) and 14 females (48.27\%) were found to be positive, (Table 3 ). Seasonal dynamics of the identified Cryptosporidium. parvum revealed that, the highest prevalence was found in winter 18 (60\%), followed by autumn 6 (20\%), then spring 4 (13.3\%) and summer 1 (3.33\%), (Table 4, Fig. 4).

Eimeria spp.: Out of 120 examined camel's fecal specimens 16 (13.33\%) were found to be positive for Eimeria spp., (Table 1). Out of 16 cases, 9 male (56.25\%) and 7 female (43.75\%) were found to be positive, (Table 3). Seasonal dynamics of the identified Eimeria spp. indicated that, the highest prevalence was found in winter $11(36.66 \%)$ followed by autumn 5 (16.66\%), no Eimeria spp. oocysts were detected during spring and summer, (Table 4). Three Eimeria spp. were identified, E.pellerdyi 8 (50\%), E.dromedarii 5 (31.25\%) and E.cameli 3 (18.75\%). (Fig. 5).

Blantidium coli: Out of 120 examined camel's fecal specimens 5 (4.16\%) were found to be positive for Balantidium coli, (Table 1). Out of 5 cases, 2 male (3.03\%) and 3 female (5.55\%) were found to be positive, (Table 4). Seasonal dynamics of the identified Blantidium coli indicated that, the highest prevalence was found in spring $2(6.66 \%)$ and summer $2(6.66 \%)$ and followed by autumn $1(3.33 \%)$, and no detection in winter $0(0 \%)$, (Table 4 , Fig. $6)$.

Table 4 Seasonal prevalence of enteric protozoa infecting dromedary camels

\begin{tabular}{lcccccc}
\hline Seasons & $\begin{array}{c}\text { No of the examined } \\
\text { camels }\end{array}$ & $\begin{array}{c}\text { Cryptosporidium } \\
\text { parvum }\end{array}$ & $\begin{array}{c}\text { Eimeria } \\
\text { spp. }\end{array}$ & $\begin{array}{c}\text { Balantidium } \\
\text { coli }\end{array}$ & $\begin{array}{c}\text { Giardia } \\
\text { intestinalis }\end{array}$ & $\begin{array}{c}\text { Diplodinium } \\
\text { spp. }\end{array}$ \\
\hline Winter & 30 & $18(60.0)$ & $11(36.7)$ & $0(0.0)$ & $0(0.0)$ & $19(63.3)$ \\
Spring & 30 & $4(13.3)$ & $0(0.0)$ & $2(6.7)$ & $3(10.0)$ & $18(60.0)$ \\
Summer & 30 & $1(3.3)$ & $0(0.0)$ & $2(6.7)$ & $3(10.0)$ & $17(56.7)$ \\
Autumn & 30 & $6(20.0)$ & $5(16.7)$ & $1(3.3)$ & $0(0.0)$ & $16(53.3)$ \\
Total & 120 & $29(24.2)$ & $16(13.3)$ & $5(4.2)$ & $6(5.0)$ & $70(58.3)$ \\
\hline
\end{tabular}

Data presented as number of +ve cases (\%) 


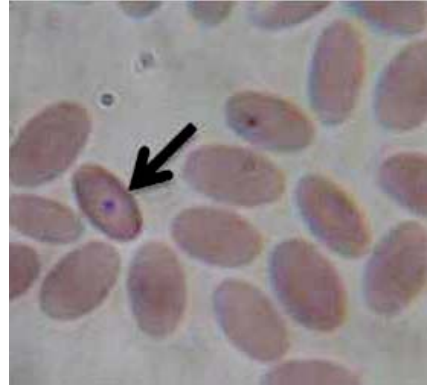

Figure 1: Theileria spp. (100x)

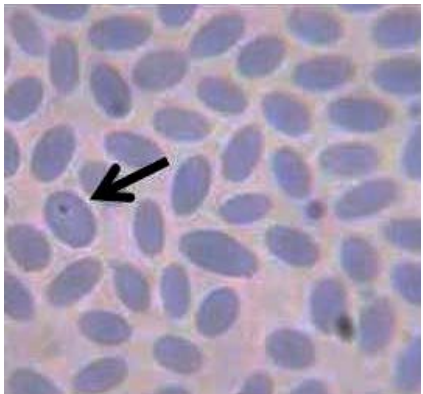

Figure 2: Anaplasma marginale (100x)

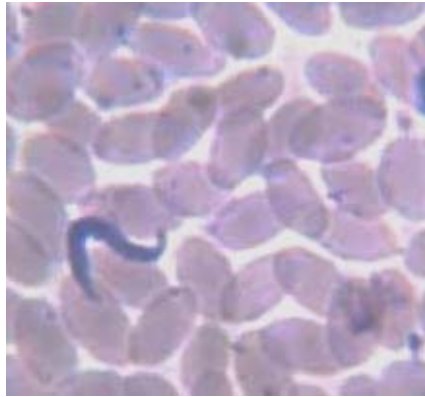

Figure 3: Trypanosoma evansi (100x)

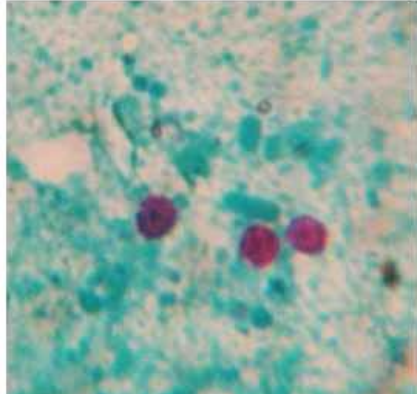

Figure 4: Cryptosporidium parvum (100x)
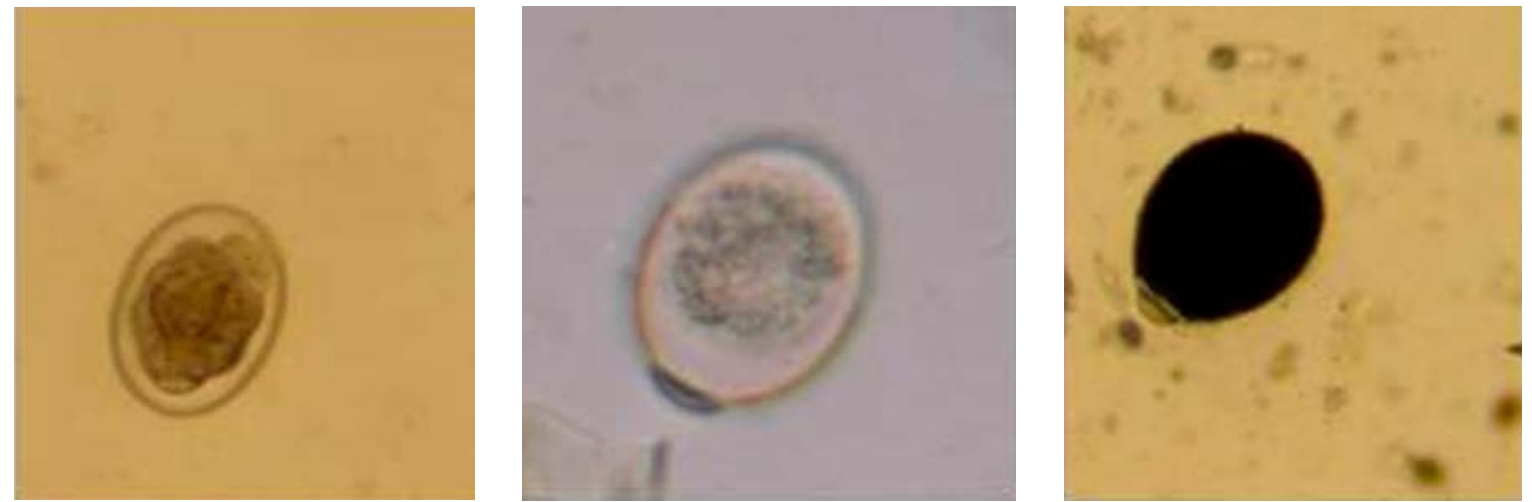

Figure 5: Oocysts of the three Eimeria spp. in the examined camel's fresh fecal specimens (40x )
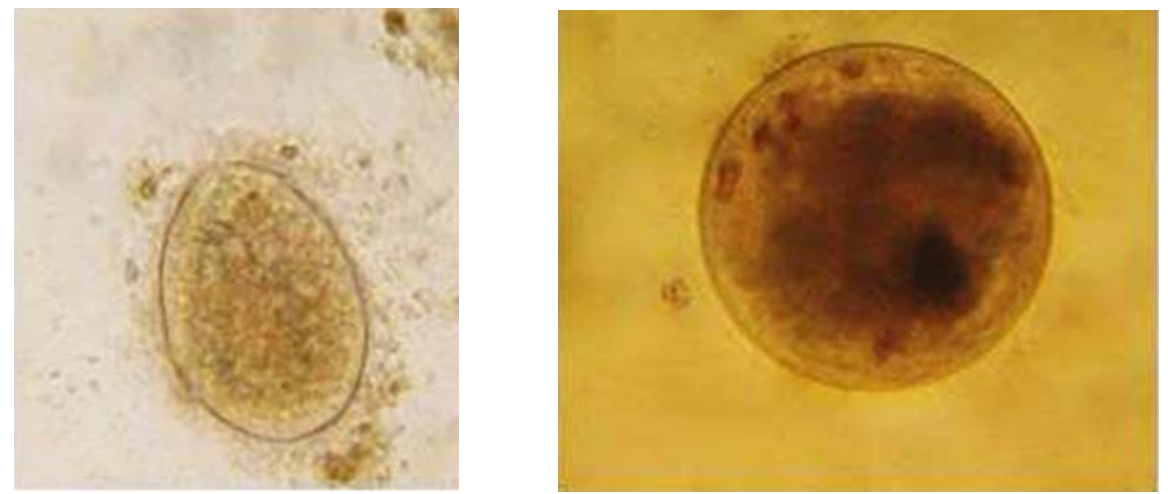

Figure 6: Trophozoite (Left) and cyst (Right) of Balantidium coli in the examined camel's fresh fecal specimens (40x)

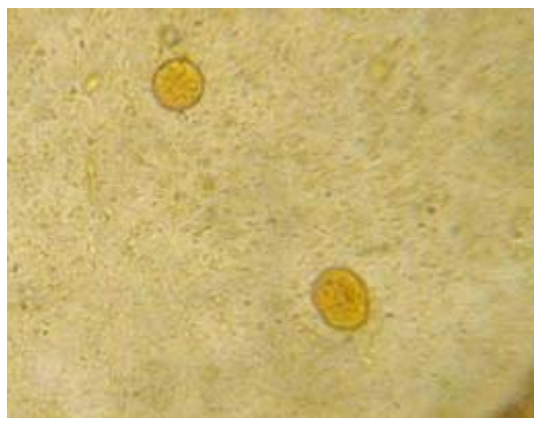

Figure 7: Giardia intestinalis in the examined camel's fresh fecal specimens (40x)

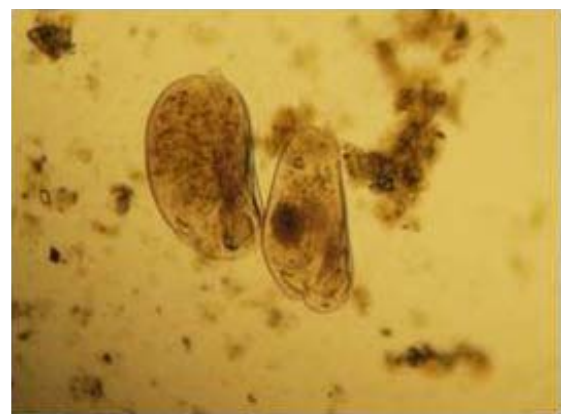

Figure 8: Trophozoite of Diplodinium spp. in the examined camel's fresh fecal specimens (40x) 
Giardia intestinalis: Out of 120 examined camel's fecal specimens $6(5 \%)$ were found to be positive for Giardia intestinalis, (Table 1). Out of 6 cases, 2 male (33.33\%) and 4 female (66.66\%) were found to be positive, (Table 4$)$. Seasonal dynamics of the identified Giardia intestinalis. indicated that, the highest prevalence was found in spring and summer $3(10 \%)$ and no detection in both winter and autumn, (Table 4, Fig. 7).

Diplodinium spp. :Out of 120 examined camel's fecal specimens 70 (5\%) were found to be positive for Diplodinium spp., (Table 1). Out of 70 cases, 35 male (50\%) and 35 female (50\%) were found to be positive, (Table 4). Seasonal dynamics of the identified Diplodinium spp. indicated that, the highest prevalence was found in winter 19 (63.33\%), followed by spring 18 (60\%), then summer 17 (56.66\%) and autumn 16 (53.33\%), (Table 4, Fig. 8).

\section{Discussion}

The present study was dedicated to investigate freshly examined slaughtered camels for the presence of blood and enteric protozoa. The study revealed that, the prevalence of Trypanosoma evansi, Theileria spp., Anaplasma marginale, Cryptosporidium parvum, Eimeria spp., Blantidium coli, Giardia intestinalis and Diplodinium spp. was $1.66,45.82,15.8,24.16,13.33,4.16,5 \%$ and $58 \%$ respectively.

Concerning, the prevalence of Theileria spp. infecting dromedary camels was $45.8 \%$ that somewhat similar to the results obtained by El-Fayoumy et al. (2005), they detected the overall prevalence to be $44.8 \%$. These results were lower than that obtained by El-Refaii et al. (1998), who detected that, the overall prevalence was $62.1 \%$. In contrast, these results was higher than that obtained by Hamed et al. (2011), Qalban et al. (2011) and Hekmatimoghaddam et al. (2012), they mentioned 6.75, 10 and $15.79 \%$ respectively. Borji et al. (2009) and Sloboda et al. (2011) found no positive camels in their survey. These variations in the different results may be attributed to different localities, population density of camels, environment, hygienic measures and camel management.

Seasonal profile of the identified Theileria spp indicated that the highest incidence in summer reached to $50 \%$ This result similar to that obtained by, Mahran (2004) found that, Theileriosis was most prevalent during summer. This might be due to correlation between the infestation and density of tick population.

Regarding, the prevalence of Anaplasma marginale infecting dromedary camels was $15.8 \%$. This result disagreed with Borji et al. (2009), who did not find Anaplasma organisms in their epidemiologic study, while as Ismail et al. (2013) detected only one positive case for Anaplasma organisms in their epidemiological study of 173 camels. Concerning, the prevalence of Anaplasma marginale among sex categories was 10 male and 9 female which revealed that, no significant difference between sex categories.

Regarding, the prevalence of Trypanosoma evansi infecting dromedary camels was $1.66 \%$ relatively similar result obtained by Laila et al. (2001) and Abd-Elmaleck et al. (2014), was $4.1 \%$ and $3.06 \%$,. On other hand, our result lower than that obtained by Mahran (2004) (11.6\%) and Baraka et al. (2005) (26.6\%). Such variations in prevalence of blood parasites may ascribe to several reasons, including different localities, population density of camels, environment and hygienic measures. Concerning the prevalence of Trypanosoma evansi among sex categories was $50 \%$ male and $50 \%$ female which revealed that, no significant difference between sex categories. Our result were similar to Bogale et al. (2012) who, detected that no statistically significant difference. Regarding the seasonal prevalence of Trypanosoma evansi. infecting camels in the present study, we found Trypanosoma evansi only in winter and autumn $3.33 \%$. This result nearly similar to that obtained by Zayed et al. (2010) who detected that, the highest prevalence rate was observed in winter $20 \%$ followed by summer $10 \%$, spring $2.08 \%$ and $0 \%$ in autumn. The seasonal variation in prevalence of blood protozoa may be attributed to the different environmental changes; temperature, humidity and rainy or dry season, animal factors, farm management other stress factors and Tabanidae which considered the main mechanical vectors of $T$. evansi.

The current study showed that the incidence rate of Cryptosporidium parvum. infecting dromedary camels was $24.16 \%$ that similar to some extent to the results obtained by Nazifi et al. (2009), Sazmand et al. (2012b) and AbdelWahab and Abdel-Maogood, 2011, they detected the overall prevalence to be 19.9, 20.33 and $19.3 \%$ respectively. In contrary our current results were lower than that obtained by Razawi et al. (2009). As well as, our 
results was higher than that obtained by Borji et al. (2009), Saleh and Mahran (2007) and Yakhchali and Moradi (2012), they detected the overall prevalence to be $1.96,3.37$ and $10 \%$ respectively. These variations could be due to the difference in the environmental condition and hygienic measures. Concerning the seasonal prevalence of Cryptosporidium parvum. in the current study, the highest prevalence rate was detected to be $60 \%$ in winter followed by autumn $20 \%$, spring $13.33 \%$ then summer $3.33 \%$. This result was nearly similar to the result that, obtained by Mohamed (2013) in Egypt, who detected that, the seasonal variation of Cryptosporidium spp. was higher in spring $13.33 \%$, followed by winter $10.48 \%$, autumn $7.62 \%$ then summer $4.76 \%$. Concerning, the prevalence of Cryptosporidium spp. among sex categories was $12.5 \%$ male and $11.6 \%$ female which revealed that, no significant difference between sex categories. Our result were nearly similar to Sazmand et al. (2012b) whose, Statistical analysis showed no significant relation between infection and sex.

Eimeria spp. infecting dromedary camels, the results showed that the incidence rate $13.33 \%$ that similar to the results obtained by Yakhchalim and Cheraghie (2007), ElSalahy et al. (2000), Kawasmeh and El-Bihari (1983), Abubakr et al. (2000), Harfoush and Abd El-Aal (2007) and Yakhchali and Athari (2010), they detected the overall prevalence to be $12.8,13.3,14,15.3,18.7$ and $20.73 \%$ respectively. Vice versa, the current results were lower than that obtained by Mohamed (2013), Wahib and Magda (2002), El-Metenawy (1998), Rangarao and Sharma (1997), Kasim et al. (1985) and Biu et al. (2003), they detected that the overall prevalence to be 24.29, $31.4,34,40,41.6$ and $48.9 \%$ respectively. As well as, our results were higher than that obtained by Mahran (2006) and Sazmand et al. (2012a); they detected the overall prevalence to be 10.94 and $9.51 \%$ respectively.

Concerning the seasonal prevalence of Eimeria spp. in the current study, the highest prevalence rate was detected to be $36.66 \%$ in winter followed by autumn $16.66 \%$ and $0 \%$ in both spring and summer. This result was nearly similar to the result that, obtained by Borji et al. (2009) in Iran who, detected that, the seasonal prevalence of infection with Eimeria spp. of camels was $38.29 \%$ in winter followed by autumn $17.39 \%$, summer $15.62 \%$ and spring $11.23 \%$. Concerning, the prevalence of Eimeria spp. among sex categories was $7.5 \%$ male and $5.83 \%$ female. The most prevalent Eimeria species in this work was $E$. cameli, followed by E. dromedarii then, E. pellerdyi. Similar results were obtained by Mahran (2006) in Egypt.

Concerning the prevalence of Blantidium coli infecting dromedary camels was $4.16 \%$ which agreed to Wahba and Radwan (2009), El-Tayar et al. (2012) and Har foush and Abd El-Aal (2007), who detected that the incidence rate of $4.76 \%$ in Cairo, $3.3 \%$ and $3.73 \%$ in Matrouh respectively. In addition, our results were lower than that obtained by Rewatker et al. (2009), Partani et al. (1998) and Tekle and Abebe (2001), who detected prevalence rate of $7.14,30.2$ and $11.92 \%$ respectively. There are a few reports about the presence of $B$. coli in camel fecal samples. Among sex categories females was higher than males. This might be attributed to stress of pregnancy, lactation and hormonal factors. The reservoir host for $B$. coli in Islamic countries is unknown. Camel has been proposed as a reservoir host for B. coli in Islamic countries, however, there are few documents.

The incidence rate of Giardia spp. in this study was 5\% while Beck et al. (2011) confirmed the absence of Giardia spp. in the captive camels in zoo of Croatia this in contrast with Radhy et al. (2013), who stated incidence rate of $100 \%$. Concerning the prevalence of Diplodinium spp., infecting dromedary camels was (5\%) limited number of studied have been reported. Among sex categories females was higher than males. This might be attributed to stress of pregnancy, lactation and hormonal factors. These differences in enteric protozoans could be attributed to difference in environment condition between the countries besides the difference in the number of camels included in these studies

\section{REFERENCES}

Abd-Allah, A. (2007): Studies on some infection skin affections in camels, PhD. Thesis (Infectious diseases) Faculty of Vet. Med. Beni suef University, Egypt.

Abdel-Wahab, A. and Abdel-Maogood, S. (2011): Identification of Cryptosporidium species infecting camels (Camelus dromedarius) in Egypt. Journal of American Science 7(2):609-612.

Abd-Elmaleck, S.B.; Abed, H.G. and Mandour, M. A. (2014): Some Protozoan Parasites Infecting Blood of Camels (Camelus dromedarius) at Assiut Locality, Upper Egypt J . Bacteriol Parasitol 5 (2): 1-7.

Abubakr, M.I.; Nayel, M.N.; Fadlalla, M.E.; Abdelrahman, A.O.; Buobeida, S.A. and Elgabara, Y.M. (2000): Prevalence of gastrointestinal parasites in young camels in Bahrain.Reviueelev .Med. Vet. Pays.Trop ., 53(3): 267-71. 
Adam, K.M., Paut, G.J. and Zaman, V. (1971): Medical and Veterinary Protozoology (An Illustrated Guide), Revised Edition. Longman Group Hoare C (1972). Evolutionary trends in mammalian trypanosomes. Adv. Parasitol. 5:41. Limited, Great Britain.

Amer, S., Ryu, O., Tada, C., Fukuda, Y., Inoue, N. and Nakai, Y. (2011): Molecular-identification and phylogenetic analysis of Trypanosoma evansi from dromedary camels (Camelus dromedarius) in Egypt, a pilot study. ActaTrop. 117, 39-46.

Baraka, T.A.; Abdou, T. A.; and Abou-Elnga, R. (2005): Clinical and laboratory studies of rumen performance and blood hemato-biochemical status in Trypanosome infected camels. 4th Int. Sci. Conf. April 2005, 1- 14.

Beck, R., Sprong, H., Bata, I., Lucinger, S., Pozio, E., Biu, A.A., et al. (2011): Dromedarian coccidiosis: A Prevalence study in camels in Maiduguri, Northeastern Nigeria. Stud. Res. Vet. Med. Bucharest., 9 (1): 187-192.

Biu, A.A., Zanaga, P.I., Gulani, A.I. (2003): Dromedarian coccidiosis : A Prevalence study in camels in Maiduguri, Northeastern Nigeria. Stud. Res. Vet. Med. Bucharest., 9 (1): 187-192.

Boulter, N., Hall, R. (1999): Immunity and vaccine development in the bovine theilerioses. Adv. Parasitol. 44, 41-97.

Borji, H., Ramzi, G.H. and Parandeh, S, (2009): Epidemiological study on haemoparasites of dormidary (Camelus dromedaries) in Iran. Journal of Camel Practice Reasearch 16 (2): 217-219.

Bogale, B., Kelemework, F., and Chanie, M. (2012). Trypanosmosis in Camel (Camelus dromedaries) in DeloMena District, Bale Zone, Oromia Region, Southwest Ethiopia. Acta Parasitologica Globalis 3(1): 12-15.

Chhabra, M.B. and Sangwan, A.K. (2006): Parasitic diseases of camels - An update, 1. Protzoal diseases. Journal of camel Practice Research 13(1): 7-14.

Derakhshanfar, A., Mozaffari, A.A. and Mohaghegh, Z. (2010): An outbreak of Trypanosomiasis (Surra) in Camels in the Southern Fars Province of Iran: clinical, hematological and pathological findings. Res. J. Parasitol. 5, 23-26.

Duszynski, D.W., Wilson, W.D., Upton, S.J. and Levine, N.D. (1999): Coccidia (Apicomplexa: Eimeriidae) in the Primates and the Scandentia. International Journal of Primatology 20: 761-797.

El-Fayoumy, M.M., AbouElnga, T.R., Abd El-Baky, S.M.M. and Abdou, T.A. (2005) :Prevalence and of camel theileriosis and its vector tick in North Coast of Egypt. Journal of the Egyptian Veterinary Medical Association 65, 291-302.

El- Metenawy, T. M. (1998): Studies on parasites infecting camels (Camelus dromedarius) in Al-Qassim Region, Saudi Arabia. Saudi Comp. Vet. Med. J., 1(2): 341-349.

El-Refaii, M.A.H., Wahba, A.A. and Shehab, G.J. (1998): Studies of Theileria infection among slaughtered camels in Egypt. The Egyptian Journal of Medical Science 19, 1-17.
El-Salahy, M., Monib, M. and Arafa (2000): Parasitological studies of some Gastrointestinal Parasites of camels in Assiut Governorate with special reference to zoonotic Nematodes. Assiut Vet. Med. J., 43 (86): 280-294.

El-Tayar, A.A., Fadly, R.S. and Abd El-Aal, A.M.I. (2012): Incidence and Survey of Gastro intestinal Parasites of Camels in Behera and Matrouh Province. Egypt. J. Agric. Res., 90(1): 495-516.

Hamed, M.I., Zaitoun, A.M.A., El-Allawy, T.A.A. and Mourad, M.I. ( 2011): Investigation of Theileria camelensis in camels infested by Hyalomma dromedarii ticks in Upper Egypt. J Adv Vet Res, 1: 4-7.

Harfoush, M.A.M. and Abd El-Aal, A.M.I. (2007): Studies on some enteric protozoa in camels. Special Issue for the $3^{\text {rd }}$ International Scientific Conference, Egypt, Vet. Med. Soc. Paras. J., IV (1): 865-878.

Hekmatimoghaddam, S.H., Sazmand, A. and Rasooli, A. (2012): Laboratory tests in dromedary camels naturally infected with piroplasms in Iran: study and review of literature. Journal of Camel Practice Research. Vol. 19 No. 2. P 217-221.

Henriksen, S.A. and Pohlenz, J.F.L. (1981): Staining of Cryptosporidia by modified Ziehl-Neelsen technique. Acta. Vet. Scand., 22:495-596.

Higgins, A. J. (1986): The camel in health and disease. Baillere, Tindall, London, Philadelphia Toronto

Unter, P.R., and Thompson, R.C.A., (2005). The zoonotic transmission of Giardia and Cryptosporidium. International Journal of Parasitology. 35, 1181-1190.

Ismail, B. A., Ayman, A.S., Ahmed, F.K. and Mohamed A. A. (2013): Clinical, Haematological and Biochemical Alterations Associated with an Outbreak of Theileriosis in Dromedaries (Camelus dromedarius) in Saudi Arabia. Pak Vet J, 34(2): 09-213.

Kasim, A. A., Hussein, H. S. and Al Shawa, Y. R. (1985): Coccidia in camels (Camelus dromedarius) in Saudi Arabia. J. Protozool., 32 (1): 202-203.

Kaufmann, J. (1996): Parasitic infections of domestic animals. Birkhauserverlog, Germany, Pp. 262-263.

Kawasmeh, Z. A. and El-Bihari, S. (1983): Eimeria cameli (Henery and Masson, 1932) Reichenow, 1952: redescription and prevalence in the Eastern Province of Saudi Arabia. Camel Vet., 73(1): 58-66.

Laila, S. Ahmed; Allawy, T. A. and Mohamed, A. A. M. (2001) : Some epidemiological aspects of camel trypanosomiasis in Upper Egypt. International Conference on Reproduction and Production of Camelids, Al-Ain, United Arab Emirates, p. 14.

Mahran, O. M. (2004): Some studies on blood parasites in camels (Camelus dromedarius) at Shalateen city, Red Sea Governorate. Assuit Vet. Med. J., 50 (102) : 172-184.

Mahran, O. M. (2006): Some epidemiological and parasitological studies on prevalence of gastrointestinal parasites of dromedary camels at Shalatin Region, Red Sea governorate, Egypt and trials of treatment. Assiut Vet. Med. J., 52 (111): 149-162. 
Mohamed, O.A.S. (2013): Studies on coccidial parasites in Camels. Thesis for the PhD. F of Veterinary Medical Science. Fac. Vet. Med. Zag. Univ., Egypt.

Nazifi, S., Behzadi, M. A., Haddadi, S. H., Jahromi, A. R., Mehrshad, S. and Tamadon, A. (2009): Prevalence of Cryptosporidium isolated from dromedary camels (Camelus dromedarius) in Qeshm Island, Southern Iran. Compar. Clin. Path., 19 (3): 311-314.

Partani, A. K., Kumar, D. and Bhan, A.K. (1998): Prevalence of Balantidium Coli infection in camels at Bikaner, Rajasthan. J. Vet. Parasitology, 12 (2): 118-121.

Qablan, M.A., Slobod, M., JirKů, M., Obornik, M., Dwairi, S., Amr, Z.S., et al. (2011): Quest for the piroplasms in camels: identification of Theileria equi and Babesia caballi in Jordanian dromedaries by PCR. Veterinary Parasitology 186 (3-4): 456-460.

Radhy, A.M., Khalaf, J.M. and Faraj, A.A. (2013): Some Gastro-intestinal Prorozoa of Zoonotic Importance Observed In Captive Animals of Al- Zawraa Zoo in Baghdad. I.J.S.N., VOL. 4(3) 2013: 567-570.

Rangarao, G.S.C. and Sharma, R.L. (1997): Intestinal Coccidiosis due to Eimeria rajasthani in camel (Camelus dromedarius) Ind. Vet. J., 74(5): 427-428

Razawi, S. M., Oryan, A., Bahrami, S., Mohammadalipour, A. and Gowhar, M. (2009): Prevalence of Cryptosporidium infection in camels (Camelus dromedarius) in a slaughter house in Iran. Trop. Biomed., 26 (3): 267-273.

Rewatkar, S. G., Deshmukh, S. S., Deshkar, S. K., Maske, D. K., Jumde, P. D. and Bhangale, G. N. (2009): Gastrointestinal helminthes in migratory camel. Vet. World, 2 (7): 258.

Saleh, M.A., Mahran, O. M. (2007): A preliminary study on cryptosporidiosis in dromedary camels at Shalatin Area, Egypt. Assiut Vet. Med. J., 53 (112): 195-208.

Sazmand, A., Hamidinejat, H., Hekmatimoghaddam, S., Asadollahi, Z. and Mirabdollahi, S. (2012a): Eimeria infection in camels (Camelus dromedarius) in Yazdprovince, central Iran. Trop. Biomed., 29 (1): 77-80.

Sazmand, A., Rasooli, A., Nouri M., Hamidinejat H. and Hekmatimoghaddam, S. (2012b): Prevalence of Cryptosporidium spp. in Camels and linvolved People in Yazd province, Iran. Iranian J. Parasitol., 7(1): 80-84.

Selim , H.M, Imai S, Yamato O, Miyagawa, E. and Maede Y. (1996): Ciliate protozoa in the forestomach of the dromedary camel, (Camelus dromedarius), in Egypt, with description of a new species. The Journal of Veterinary Medical Science, 58(9):833-837.
Sloboda, M., Jirku, M., Lukesova, D., Qablan, M., Batsukh, Z., Fiala, I., Horin, P., Mordy, D. and Lukes, J. (2011): A Survey for piroplasmids in horses and Bactrin camels in North Eastern Mongolia. Veterinary Parasitology 179 (1-3):246-249.

Soulsby, E. J. L. (1982): Helminthes, arthropods and protozoa of domesticated animals. $7^{\text {th }}$ Ed. The English language book society. Balliere, Tin-dall and Cassel. London.

Stewart, N.P., Uilenberg, G., d. and Vos, A.J. (1996): Review of Australian species of Theileria, with special reference to Theileria buffeli of cattle. Trop Anim Health Prod 28: 81-90.

Tekle, T. and Abebe, G. (2001): Trypanosomiasis and helminthes: Major health proplems of camels (Camelus dromedaries) in the Southern Rangelands of Borena, Ethiopia. J. of Camel Practice and Research, 8(91): 39-42.

Wahba, A.A. and Radwan, I.G.H. (2009): Some studies on Protozoal Parasites of Camels in Egypt. Egypt. J. Comp. Path. \& Clinic. Path. Vol. 22 No. 2(3): 41-53.

Wahib, A. A. and Magda, E.A. H. (2002): Animal Health Research Institute, Agricultural Research Center, Ministry of Agriculture, Dokki, Giza. Manuscript July 2002.

Wang, R., Zhang, L., Ning, C., Feng, Y., Jian, F., Xiao, L., et al. (2008): Multilocus phylogenetic analysis of Cryptosporidium andersoni (Apicomplexa) isolated from a Bactrian camel (Camelus bactrianus) in China. Parasitol Res. 2008; 102:915-920.

Yakhchali, M. and Athari, S.H. (2010): A study on prevalence of Eimeria spp. infection in camels of Tabriz region, Iran. Archives of Razi Institute, 65(2): 111-115.

Yakhchali, M. and Cheraghie, E. (2007): Eimeriosis in bactrian and dromedary camels in the Miandoab region, Iran. Acta Vet., 57(5-6): 545-552.

Yakhchali, M. and Moradi, T. (2012): Prevalence of Cryptosporidium-like infection in one-humped camels (Camelus dromedarius) of north western Iran. J. Parasitol., 19(1): 71-75..

Zayed, A.A., Habeeb, S.M., Allam, N.A.T., Ashry, H.M.Z., Mohamed, A.H.M., Ashour, A.A., Taha, H.A., 2010. A critical comparative study of parasitological and serological differential diagnostic methods of Trypanosoma evansi infections in some farm animals in Egypt. Am.-Eurasian J. Agr. Environ. Sci. 8, 633-642. 